\title{
An Assessment of Quality Issues in the provision of Early Childhood Development B in Zimbabwe
}

\section{J. Musiyiwa and E.Chikwiri}

Women`s University in Africa, 459 Arcturus Road, Manresa Park. Harare, Zimbabwe

\section{ABSTRACT}

The study sought to assess the quality of service delivery for the Early Childhood Development B (ECD B) programme in Zimbabwe. The study covered all the ten provinces of Zimbabwe and adopted both qualitative and quantitative approaches. The qualitative approach was largely used to elicit views on quality provision of ECD B in Zimbabwe through the use of Focus Group Discussions, interviews, document analysis and observations. Questionnaires were used to solicit information from key informants such as head teachers, teachers-in-charge and teachers. The population from which the sample was drawn included all primary schools, Education officials at district, provincial and head office levels as well as registered ECD B centres in Zimbabwe. Random, convenience and purposive sampling procedures were used to select the study sample. The study used two types of quality indicators for Early Childhood Development programmes namely structural and process quality indicators. According to Lamb (2000) structural quality indicators of ECD programmes include: teacher-pupil ratio (number of children per teacher), qualifications, experience and working conditions of teachers. Process quality indicators of ECD programmes include: the physical environment (consisting of indoor and outdoor facilities), curriculum and assessment. Findings revealed ${ }^{*}$ Correspondence to Author: E.Chikwiri

Women's University in Africa, 459 Arcturus Road, Manresa Park. Harare, Zimbabwe that quality is compromised because most ECD B classes in Zimbabwe are manned by unqualified teachers because qualified teachers are still very few. Teacher effectiveness which is brought about by knowledgeable and qualified teachers is a key component of quality ECD Bprovision. The study also revealed 
that it is a challenge to get qualified teachers to work in poor rural and otherwise difficult-toreach communities thus compromising the provision of quality ECD B in these areas. The teacher-pupil ratio at ECD B level in most parts of Zimbabwe is high, that is, it is way above the stipu-lated ratio of 1:20. A desk study of the Zimbabwean ECD curriculum indicates that it is effective and of good quality in that it is inclusive, play based and activities are developmentally appropriate. It is inclusive in that it welcomes learners in their diversity and can adapt to meet their learning needs which is one of the attributes of quality educa-tion. From the information obtained, it is very clear that most indoor facilities for ECD B classes in Zimbabwe are inadequate. Most schools in all the ten provinces do not have adequate outdoor facilities for the ECD B children. The study showed that the majority of schools provide safe water for drinking and washing. It is clear from the study that most schools have separate toilets for the ECD B children. Most of the respondents from the ten provinces indicated that the ECD B teachers assess children's holistic de-velopment using developmental skills checklists. Responses from ECD B teachers in-dicated that there is inadequate support from the Ministry of Primary and Secondary Education (MoPSE) in the following areas: allowances for para-professionals, teaching and learning materials, ECD B facilities and infrastructure, capacity building work-shops, supervision by Ministry officials, and provision of circulars. The study conclud-ed that while increased enrolments may suggest school systems have increased their capacity to accommodate more children, this did not necessarily translate into improved educational quality because of inadequate financial, material and human resources. Inadequate supply of these resources has curtailed the effectiveness and efficiency of ECD B provision in Zimbabwe.

Key words: Quality, Early Childhood Development, Structural indicators, Process indicators.

\section{Introduction}

The Zimbabwean Ministry of Primary and Secondary Education made a pronouncement to increase primary schooling from seven to nine years through the introduction of Early Childhood Development A (ECD A) and Early Childhood Development B (ECD B) in 2005 ( Director`s Circular Number 12 of 2005). The ECD A class being for $3-4$ year olds while ECD $B$ is for $4-5$ year olds. The integration of ECD into the primary school system was well received and its merits in child development were appreciated throughout the country. The demand for places has however outstretched the available facilities. While some schools provided adequate facilities and resources with the support from parents, the majority fell far short of the expected provisions. This means the issue of quality ECD provision became a major concern. Improving access is not enough; the quality of the ECD programme is crucial to ensure that children develop their full potential and are ready for school. The importance of quality ECD provision is consistent with Sustainable Development Goal 4 Target 4.2 which states that, "all girls and boys should have access to quality ECD, care and pre-primary education so that they are ready for primary education". In addition, one of the six goals outlined by the World Education Dakar Framework for Action (2000) is related to the improvement of all aspects of quality education in order to achieve the identified learning outcomes. Children who do not go through a good quality ECD programme are less likely to succeed in primary school. While 
even relatively poor provision brings some benefits, the better the quality, the greater the gain. Research shows that high quality, intense early care and education programmes for children have lasting positive effects such as greater school success, higher graduation rates, lower juvenile crime and decreased need for special education services. At the same time low quality care can have harmful effects on language, social development and school performance that are difficult to amoliorate, especially in schools with fewer resources.

There is broad consensus on what constitutes quality in early education. Quality indicators in ECD constitute structural and process dimensions. These indicators are related and influence the quality of the educational experiences of ECD B children. Aspects of process quality indicators include: the physical environment (consisting of indoor and outdoor facilities), curriculum, assessment and family involvement. Structural quality indicators include : adult-child ratios (number of children per teacher), qualifications, experience and working conditions of teachers. Structural elements are more easily measured and have tended to form the basis of quality measures. This study assessed the quality of service delivery for the ECD B programme in Zimbabwe using the mentioned process and structural quality indicators.

\section{Methods}

The study was carried out within the context of the following question:

To what extent does the Zimbabwean ECD B programme meet the structural and process quality indicators?

\section{Sample and Sampling Procedures}

The following procedures were used in selecting the sample for this study: Random, purposive and convenience sampling procedures. Sampling of interviewees was done purposively. Focus Group Discussion participants were randomly selected for interviews and these included parents and school pupils. The first group of respondents was drawn from implementers of the ECD programme at school level as depicted in Tables 1 to 3 :

\section{Table 1: Distribution of ECD Implementers by Responsible Authority}

\begin{tabular}{|l|l|l|l|l|}
\hline Responsible Authority & Frequency & Percent & Valid Percent & Cumulative Percent \\
\hline Municipality & 31 & 6.5 & 6.5 & 6.5 \\
\hline Government & 77 & 16.2 & 16.2 & 22.7 \\
\hline Rural District Council & 206 & 43.4 & 43.4 & 66.1 \\
\hline Church Organisations & 77 & 16.2 & 16.2 & 82.3 \\
\hline Mine & 30 & 6.3 & 6.3 & 88.6 \\
\hline Farm & 14 & 2.9 & 2.9 & 91.6 \\
\hline Individual ownership & 19 & 4.0 & 4.0 & 95.6 \\
\hline Other & 9 & 1.9 & 1.9 & 97.5 \\
\hline No Response & 12 & 2.5 & 2.5 & 100.0 \\
\hline Total & 475 & 100.0 & 100.0 & \\
\hline
\end{tabular}

The schools were selected using purposiverandom sampling procedure. They were selected in terms of their location. ECD District Trainers guided the selection of schools in terms of the above criteria. The second group of respondents is collectively referred to as Professionals and their composition is shown in the following Table. The majority of them (67\%) were District Trainers and District Education Officers. 
Table2: Distribution of ECD Implementers by Province

\begin{tabular}{|l|l|l|l|l|}
\hline Name of Province & Number of Respondents & Percent & Valid Percent & $\begin{array}{l}\text { Cumulative } \\
\text { Percent }\end{array}$ \\
\hline Bulawayo & 43 & 9.1 & 9.1 & 9.1 \\
\hline Harare & 21 & 4.4 & 4.4 & 13.5 \\
\hline Manicaland & 63 & 13.3 & 13.3 & 26.7 \\
\hline Mashonaland Central & 73 & 15.4 & 15.4 & 42.1 \\
\hline Mashonaland East & 44 & 9.3 & 9.3 & 51.4 \\
\hline Mashonaland West & 35 & 7.4 & 7.4 & 58.7 \\
\hline Masvingo & 42 & 8.8 & 8.8 & 67.6 \\
\hline Matabeleland North & 28 & 5.9 & 5.9 & 73.5 \\
\hline Matabeleland South & 67 & 14.1 & 14.1 & 87.6 \\
\hline Midlands & 59 & 12.4 & 12.4 & 100.0 \\
\hline Total & 475 & 100.0 & 100.0 & \\
\hline
\end{tabular}

Table3: Professionals involved with the ECD programme

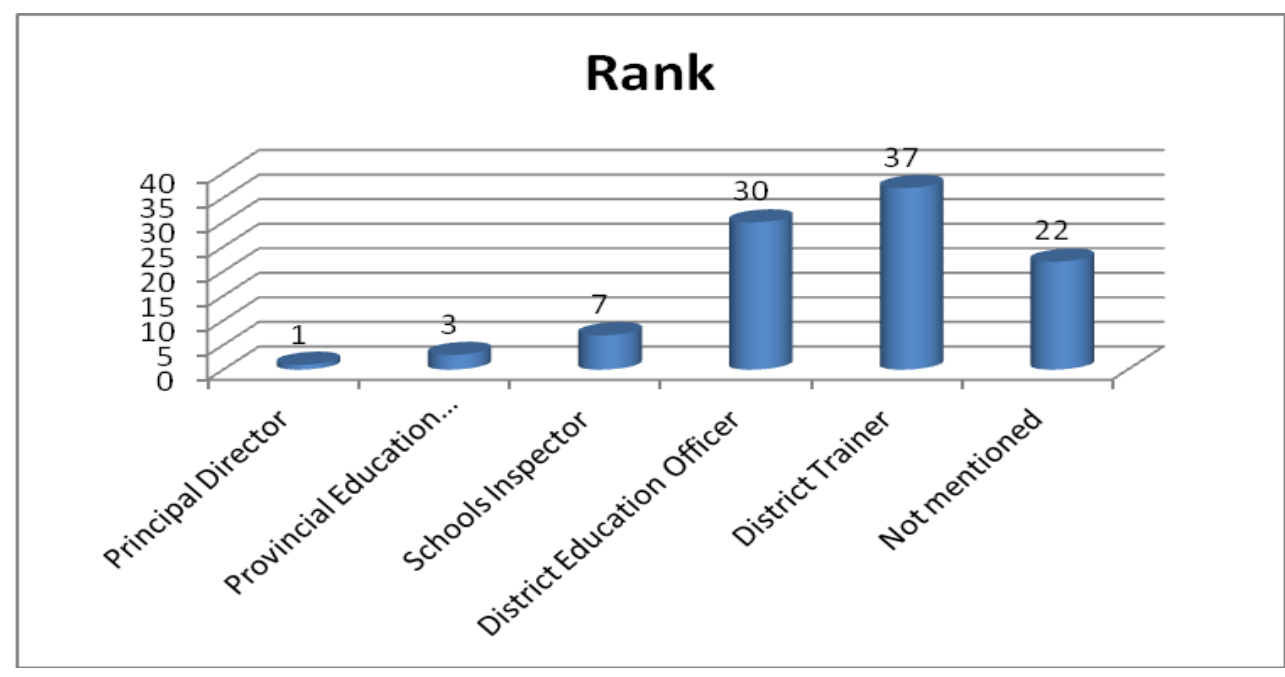

\section{Data Collection Methods and Analysis}

Data collection was done through: Focus Group Discussions, Key Informant interviews, observations and document review.

\section{Focus Group Discussions}

Participatory Reflective Analysis techniques which focused on Focus Group Discussions (FGDs) were employed with key informants to gather in-depth information, views and opinions on quality issues in ECD B provision.

\section{Key informant interviews}

Key informant interviews were conducted with selected School heads, Teachers-in-Charge and ECD $B$ teachers. Administrative professionals at the Ministry of Primary and
Secondary Education Head Office, Provincial and District Offices were also interviewed. They were interviewed as part of the knowledgeable individuals to provide the required information on quality issues in ECD provision. Based on their knowledge, purposive sampling was used to identify the appropriate interviewees.

\section{Observations}

While collecting primary data, observations were found to be useful, these were done to take note of the work from the curriculum and activities done by the teachers and children. Also, the availability and quality of infrastructure, facilities, material resources for ECD $B$ classes and general learning 
environment was partly ascertained or at least verified through observation techniques.

\section{Document review}

The study involved reviewing of the relevant Education policies such as the Education Act 1996-Revised Edition, Secretary's Circulars No. 14 of 2004, Statutory Instrument (106 of 2005), Director's Circulars Nos. 12 of 2005, 36 of 2006, 48 of 2007, 4 of 2010, documents on ECD B statistics from Head Office, the Commission of Inquiry into Education and Training (CIET) Report and other related documents to get an in-depth understanding of the context of quality ECD B provision.

\section{Data analysis}

Analysis of data was done according to emerging themes and descriptive statistics were used to unpack identified and different thematic areas.

\section{Findings}

Quality indicators emerging from the analysis were synthesized to provide a comprehensive picture of quality issues in the Zimbabwean ECD B programme. The analysis will focus on structural quality indicators first followed by process indicators.

\section{Qualifications and experience of ECD B teachers at schools}

The general consensus by the respondents was that well educated, well trained professionals are a key factor in the provision of high quality ECD programmes with the most favourable cognitive and social outcomes for children. In other words, teacher effectiveness is critical for quality ECD B provision. Responses from the ten provinces indicated that $30 \%$ of ECD B teachers are holders of either a Certificate or Diploma in Education, $60 \%$ constitutes teachers with no teaching qualification while $10 \%$ is made up of degreed teachers (Bachelor and Master of Education Degrees).

The above percentages show that most ECD B classes in Zimbabwe are manned by untrained teachers because qualified teachers are still very few. The reason for few qualified teachers dates back to 2004 when the Ministry of Primary and Secondary Education through the Secretary's circular 14 of 2004 announced that all primary schools in Zimbabwe should attach an ECD B class by 2005 , at that time there were very few teachers with specialization in that area. In addition, the few degreed teachers with specialization in Early Childhood Development in the field were in administrative positions or in institutions of higher learning. The production of ECD teachers in general has been lagging behind and hence schools are forced to employ unqualified people to teach these children. This goes against the Secretary's Circular 14 of 2004 item 2.1 which states that, 'ECD B classes should be manned by appropriately qualified teachers'. This scenario compromises quality of service delivery of the ECD B programme. Findings revealed that most ECD B classes in the rural areas and farms are the most affected by lack of appropriately qualified teachers except in urban and peri-urban areas where Diploma holders and degreed staff have been deployed by the Ministry of Public Service. The study revealed that it is a challenge to get appropriately trained teachers to work in poor rural and otherwise difficult-to-reach communities. These are generally less attractive postings. This greatly affects the quality of teaching in poor and remote areas of Zimbabwe. In other words, inequality between school locations affects the quality of teaching and learning.

However, it is not the qualification per se that has an impact on child development but the ability of better qualified teachers to create a high quality pedagogic environment that makes the difference. There is strong evidence that enriched stimulating environments and highquality pedagogy are fostered by better qualified staff; and better-quality pedagogy leads to better outcomes.

\section{Experience of ECD B teachers at schools}


About $58.2 \%$ of the respondents across the ten provinces of Zimbabwe did not mention their teaching experience. This means that most ECD B teachers are unqualified. They are not paid by the Government. Teachers with teaching experience of 1-3 years constitute $10.9 \%$, 4-6 years make up $21.4 \%$, those with 79 years' experience constitute $7.0 \%$ while those with an experience of less than I year constitute
$0.4 \%, 10-12$ years are $0.9 \%, 13-15$ years are $0.9 \%$ and over 15 years constitute $0.2 \%$. The above information shows that a greater percentage of teachers have inadequate experience and yet adequate teaching experience produces higher student results. The effect of inexperience can be a significant obstacle to quality ECD B provision thus negatively affecting student achievement.

Table4: Teacher-pupil ratio for ECD B classes

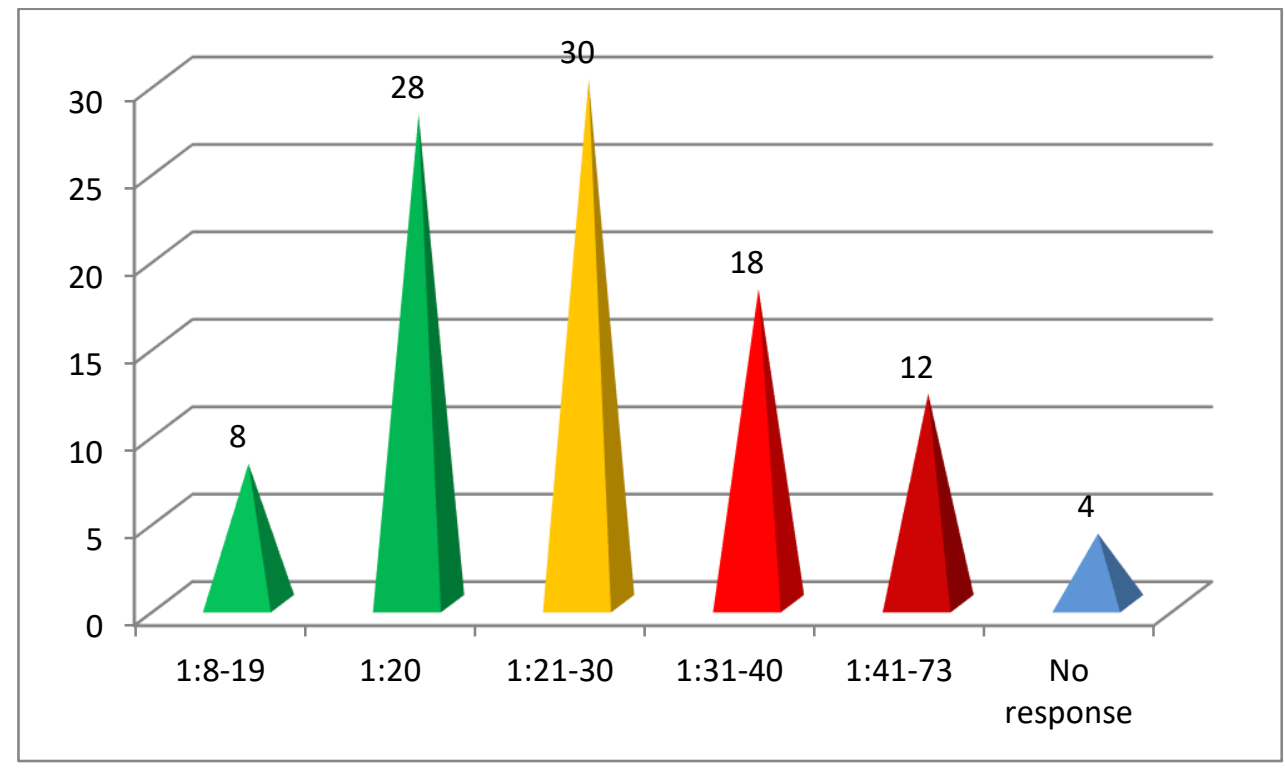

One of the major indicators of quality in ECD provision is teacher - pupil ratio. Research indicates that staff/child ratios, particularly for ECD, are a good indicator of the type of interactions that take place between adults and children (Whitebrook, 2003). The higher the ratio of adults to children, the more positive and frequent interactions are.

The study revealed that teacher-pupil ratio at ECD $B$ level varies greatly from place to place in Zimbabwe. The lowest teacher-pupil ratio of 1:8-19 constitutes $8.2 \%$, while teacher-pupil ratio of $1: 20$ is made of $28.4 \%$. The common teacher-pupil ratio is that of $1: 21-30$ which constitutes $29.9 \%$ of the responses while the ratio of $1: 31-40$ constitutes $18.1 \%$. The highest teacher-pupil ratio of $41-73$ is made up of $11.8 \%$, while $3.6 \%$ did not give any responses.
This clearly indicates that in Zimbabwe the teacher-pupil ratio at ECD $B$ level is high and way above the stipulated ratio of $1: 20$. This is against the stipulations in the Statutory Instrument 106 of 2005 Section 13(1)(a) which states that, '...one teacher to a minimum enrolment of 20 children at each center...' This is an indication that universalization of ECD B has been marked by increasingly complex internal inefficiencies in the form of congested classrooms and severe shortages of teachers. When staff have a large number of children in their care, staff/child interactions tend to be superficial.

\section{Suitability of the Curriculum}

Also, critical to quality ECD B provision is a developmentally appropriate curriculum. It facilitates quality learning, supports the holistic 
development of the child and is inclusive thus ensuring that ECD provision is equitable. $A$ desk study of the Zimbabwean ECD syllabus shows that activities match the children's stages of development. This means that the activities are developmentally appropriate, they encompass the elements of age appropriateness, that is patterns or trends in development expected of children at a particular age. The study also reveals that the Zimbabwean ECD curriculum is play based which allows children to take a lead in their own learning. This is emphasised by the Ministry of Primary and Secondary Education Statutory Instrument 106 of 2005 item 10 (2) which states that, "The ECD centre curriculum shall be appropriate to the physical, mental and social development of children below school age..."

The desk study also revealed that the Zimbabwean ECD curriculum is inclusive in that it welcomes learners in their diversity and can adapt to meet their learning needs which is one of the attributes of quality education. The quest by the Ministry of Primary and Secondary Education to provide quality inclusive education has been emphasised through the Principal Director's Circular 4 of 2010 which gives guidelines on the provision of a quality childfriendly school environment with regards to teaching and learning materials which include children with special needs.

\section{Table 5: Teacher perception of teachers' capacity to implement the ECD B curriculum}

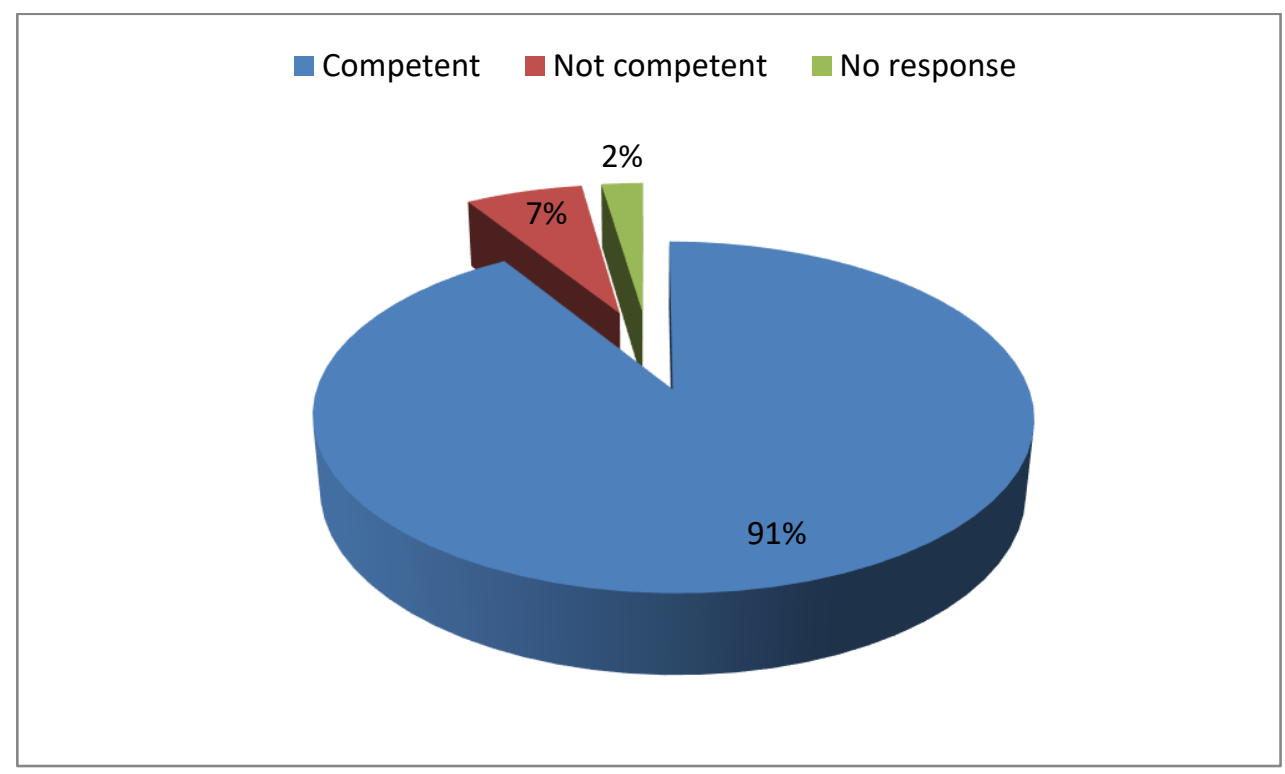

Respondents also revealed that the teaching methods used by ECD $B$ teachers suit the age group of ECD B children. A child - centred approach to ECD is advocated for in the Zimbabwean Early Childhood Development Syllabus, (2012:8). In a similar vein, the Director's circular number 12 of 2005 item 3.6 highlights that, " $\ldots$ at this stage of their development, children learn through play, hence the importance of play centres". Related to the issue of age appropriate methodology is the issue of appropriately qualified teacher with the ability to deliver quality lessons. The situation on the ground is that most ECD teachers do not have the requisite qualifications hence quality of learning is compromised. Quality educational processes require well trained teachers who are able to use learner centred teaching and learning methods and life skills approaches.

Respondents also emphasised on the need to have adequate teaching and learning materials 
in order to ensure quality provision of ECD programmes. The ECD curriculum is basically implemented through play, hence the need to have a materials-rich learning environment that is purposely arranged to allow children to explore. Exploration and manipulation of materials are pre-requisites for the construction of knowledge and if resources are not available, quality learning will not take place. The study revealed that ECD B children in rural and farm schools are mostly affected by lack of teaching and learning materials thus stifling quality educational output.

Ability to implement developmentally appropriate curriculum is one of the determinants of high quality ECD B provision. From the study, the respondents indicated that $91 \%$ of the ECD B teachers have the capacity to implement the ECD B curriculum. The ECD $B$ teachers who are not able to implement the curriculum are $7 \%$ and those respondents who did not give their responses are 2.\%. Findings revealed that the reason for being competent in curriculum implementation is that teachers (qualified and not qualified) were staff developed through workshops on the implementation of the new ECD curriculum by the Ministry of Primary and Secondary Education.

Table 6: Adequacy of ECD B Indoor Facilities

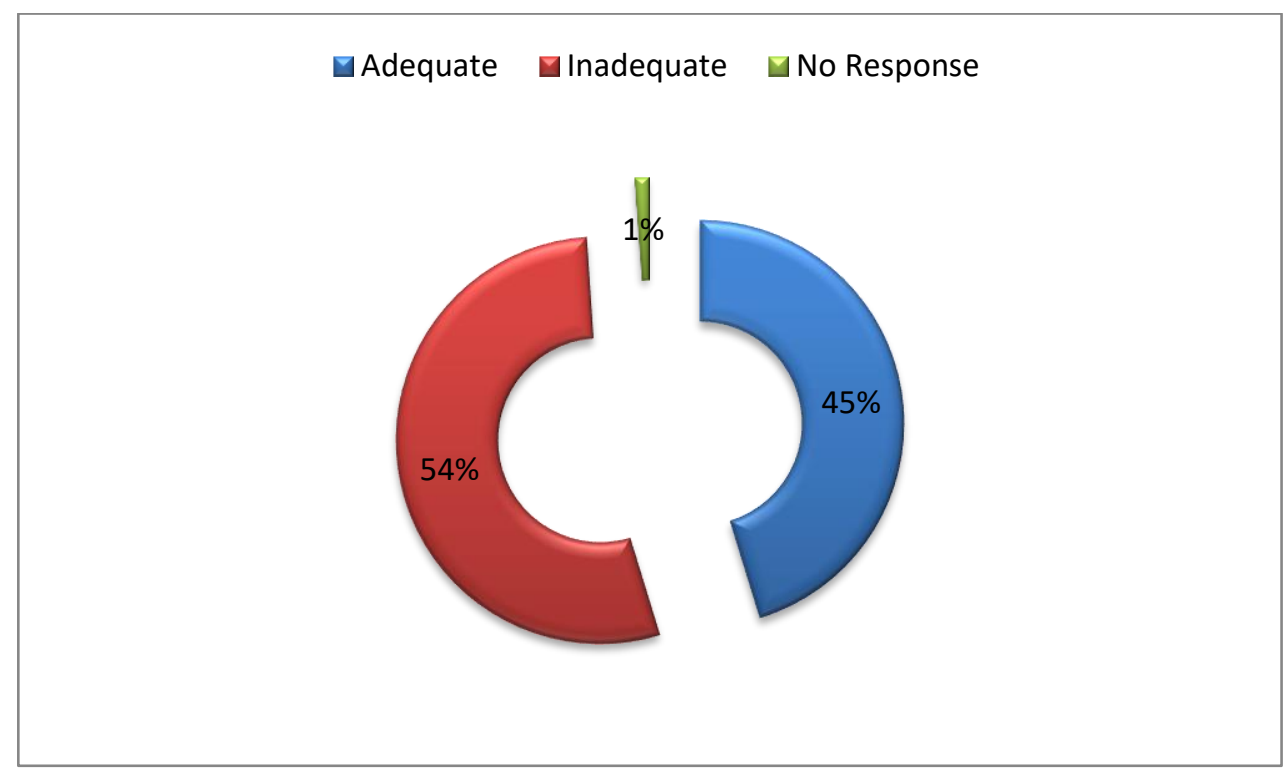

The study revealed that reasons for incompetence in the implementation of the curriculum are that:

a. The ECD B teachers are not qualified. The Early Childhood Development cur-riculum is rooted in child development, social work, family relationships, anthro-pology, health and special needs. If teachers are not competent in these areas, curriculum implementation becomes a challenge;

b. Teacher-pupil ratio is high; and

c. Inadequate resources.
As a quality assurance measure, workshops on syllabus interpretation can be held for teachers who are not competent.

\section{Adequacy of Physical facilities}

The learning environment is also considered to be part of ECD quality provision. The ECD learning environment is a mix of spaces and contexts in which children grow and learn. The environment is often referred to as "the third teacher" (after parents and educators) due to its importance in early learning. It consists of indoor and outdoor facilities, health and safety aspects (availability of toilets, clean water and 
general safety). These will be discussed in the sections that follow.

From the ten provinces $54 \%$ indicated that the indoor facilities for ECD $B$ classes are inadequate. The rest of the provinces $(45 \%)$ indicated that they have adequate indoor facilities for ECD B classes. One percent did not respond. From the information obtained, it is very clear that most indoor facilities for ECD $B$ classes in Zimbabwe are inadequate. An ideal ECD B classroom should have learning centres which are attractively organised with a particular interest in mind so that it is appealing to children (Dockett and Farmer, 2000). These centres should focus on experiences such as: dramatic play, construction, art/craft, music, manipulatives, exploration of basic materials such as sand, water, clay, puzzles; and literacy play. Quality of teaching and learning is enhanced when classrooms and indoor play areas are well equipped with developmentally appropriate materials in the mentioned learning centres to cater for the holistic development of children. The study revealed that most of the classrooms lack a variety of play materials for children to put together and take apart. The presence of such materials has been consistently linked to high quality ECD programmes.

The study revealed that some ECD B children learn under trees making it difficult to create learning centres. Findings indicated that in rural areas children from Grade One upwards are given classrooms while ECD B children attend their lessons under trees despite the harsh weather conditions they might experience. This is contrary to Statutory Instrument 106 of 2005 Section 11 item $(k)$ which clearly states that, 'adequate indoor ... storage space and clock room facilities shall be provided in respect of all early childhood development centres'.

Findings revealed that the reasons given for inadequacy of indoor facilities are that there is inadequate infrastructure due to financial constraints, lack of equipment, parents are not supporting their children, there are too many children for the facilities and vandalism by the communities. Where facilities are adequate, UNICEF equipment was given on top of what teachers had improvised.

Table 7: Adequacy of outdoor facilities for ECD B

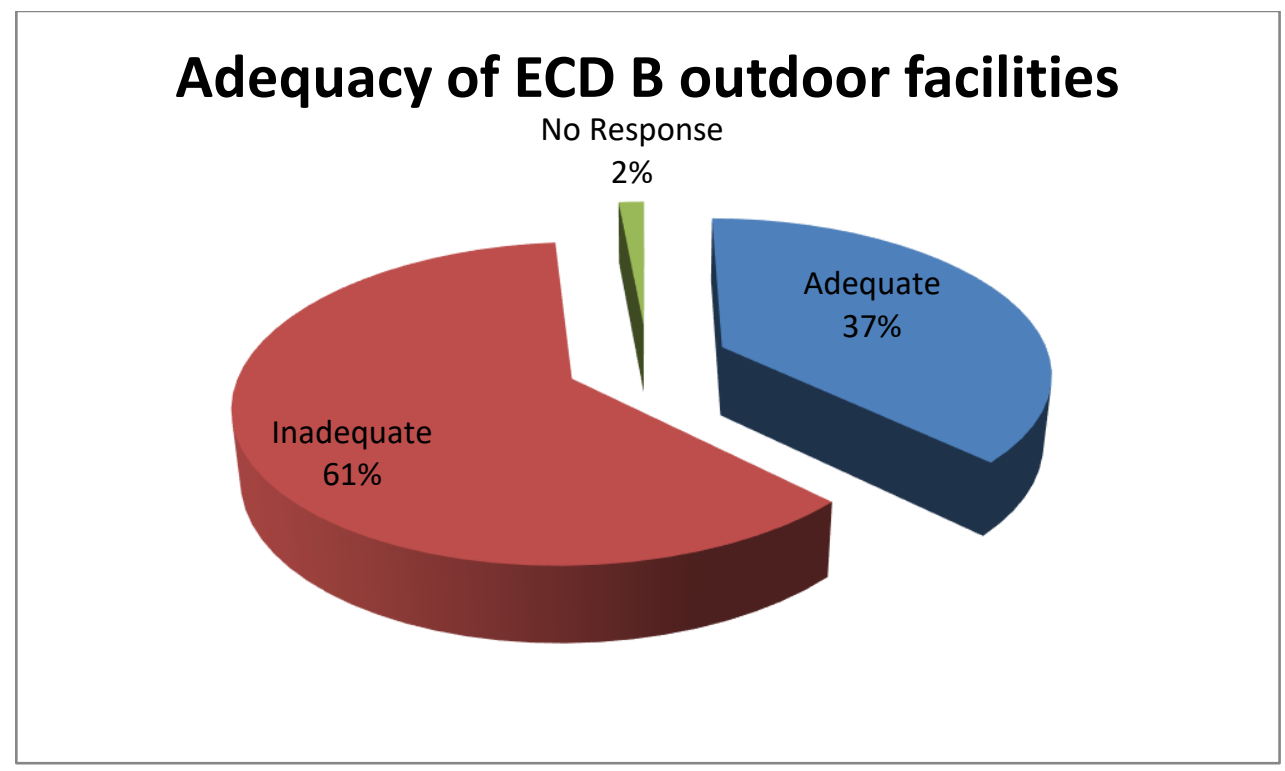

Sixty one percent $(61 \%)$ indicated that outdoor facilities are inadequate while $37 \%$ indicated that its outdoor facilities are adequate. Two percent did not give responses. From the statistics provided, it is clear that most schools in all the ten provinces of Zimbabwe do not 
have adequate outdoor facilities for the ECD B children. In contrast all the provincial ECD model centres have adequate outdoor facilities and they are in line with the Statutory Instrument 106 of 2005, Section 11 item (k) which points out that, 'adequate ... outdoor storage space and cloak room facilities shall be provided in respect of early childhood development centres'.

Where facilities are adequate, it is because parents improvised while those with inadequate facilities highlighted that this is due to insufficient funds because there are no Government grants given for that purpose and also that the facilities were vandalized by the community. Outdoor play facilities promote children's physical intellectual, social and emotional development.
The study revealed that at some schools the outdoor play area is totally neglected, a clear sign that the ECD B children are denied the opportunity to learn through play, and hence children's quality of physical development is compromised. The African Charter on the Rights and Welfare of the Child (ACRWC) (1990, Article 11) stipulates that the education of the child shall be directed to the promotion and development of the child's mental and physical abilities.

\section{Availability of separate toilets for ECD B children}

Adequate hygiene and sanitation facilities accessible to all ECD children are also considered to be part of educational quality. They are part of the learning environment.

Table 8: Availability of separate toilets for ECD B children

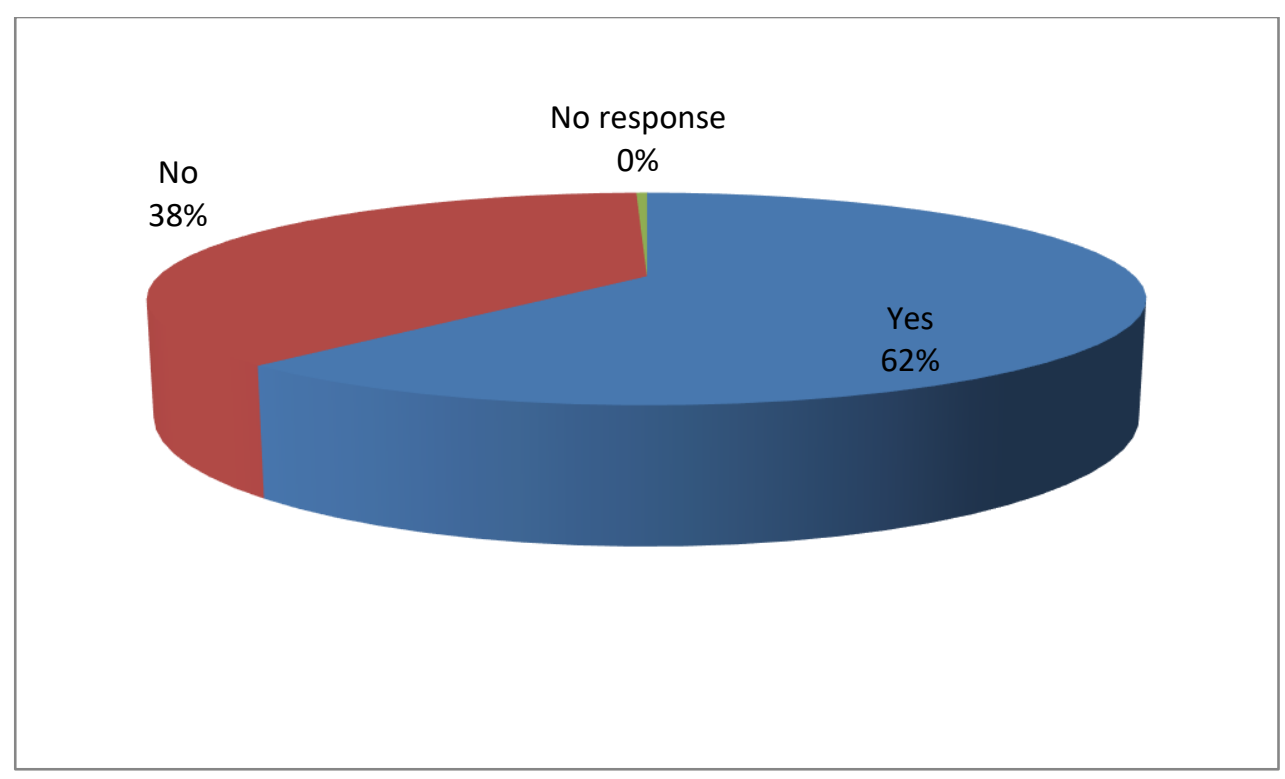

Sixty two percent of the ten provinces indicated that schools have separate toilets for staff and ECD B children while $38 \%$ indicated that they do not have separate toilets for ECD B children. It is clear from the study that most schools have separate toilets for the ECD B children. The ECD B children share the toilets with ECD A and Infant grades. Boys and girls have separate toilets. Some toilets are child sized while others are not. Schools which do not have separate toilets for ECD B children are sharing with the rest of the school. Generally, schools are making an effort to have separate toilets for ECD B children. This is in line with the Statutory Instrument 106 of 2005 Section 11 item (c) which states that, 'Separate toilet facilities shall be provided for staff...' One school in Matabeleland South (in a resettlement area) has a two-squat hole toilet for teachers only while the whole school including ECD B 
children use the bush as their toilet. Using the bush is highly unsafe because it exposes children to sexual abuse; it is also a health hazard. Bush toilets are at-risk locations which are largely unmonitored by teaching staff. Some girls at that particular school reported that boys follow them to the bush with the intention of peeping at and touching them inappropriately. Children are thus at the risk of being sexually abused.

The study also indicated that some schools do not have reliable sources of water to wash hands after visiting the bush. The Ministry of Primary and Secondary Education should enforce the need for separate toilets for ECD B children and staff in every school to minimize contraction of diseases by young children. Findings from the schools in the ten provinces revealed that they draw their water from different sources. Responses(41\%) from the ten provinces indicated that some use piped water, $35 \%$ of the responses use borehole water, $18 \%$ use both piped and borehole water, $1 \%$ have no reliable source of water, $1 \%$ use dam water while $1 \%$ and $2 \%$ use rivers and wells respectively as sources of water. One percent did not respond.

Table 9: Source of water at the schools

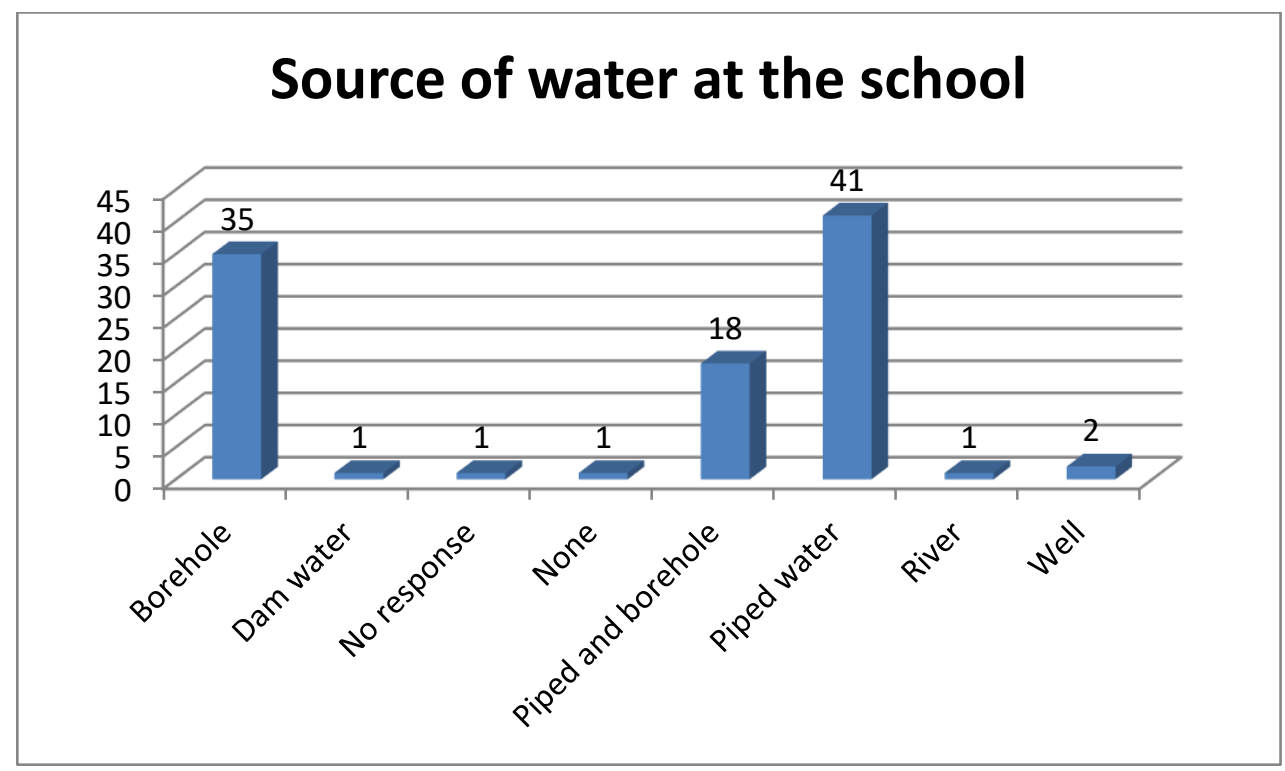

More than half of the respondents have a water source that is safe for drinking. This is in line with the Statutory Instrument 106 of 2005 Section 11 item (j) which reads '...proper facilities with running water shall be available for the washing of utensils used for milk or other food in respect of early childhood development centres.' In a similar vein, the 'Annual Statistical Report (2015:92-93) states that, "Water is available in most schools throughout Zimbabwe. However it is advisable that the schools that have no safe source of water can purify their drinking water using tablets among other methods to avoid contraction of waterborne diseases by children'.
Quality teaching and learning is not only enhanced through instructional methods, but also in assessment practices that allow teachers to gauge individual student learning and activities according to children's needs. Most of the respondents (52.8\%) from the ten provinces indicated that the ECD B teachers assess children's holistic development using developmental skills checklist. This is a record that focuses on the domains of child development which include physical, social, cognitive and emotional development. Other respondents $(9 \%)$ indicated that the ECD B teachers assess children's development $\begin{array}{ll}\text { through observations, } 10 \% \text { indicated they } \\ \text { al-of-educational-research-and-reviews/ } & 0011\end{array}$ 
assess through play and $18 \%$ indicated that they assess through continuous assessment or child study. The Principal Director's Circular 26 of 2011 item 1.0 states that, 'An improved and extended system of provision for education and development of children in this age bracket (35 -year olds) should provide the holistic development of the child ...' It is through play that children's holistic development is achieved. Hence, the methods of assessment used by the ECD $B$ teachers are appropriate. A list of record books were made available by the respondents which include: skills checklists, schemes of work, attendance registers, social records, inventories, communication books, anecdotal/incidental record books, portfolios, environmental checklists, health records, running records, plan books and time tables. All these records are kept assisting the teacher in assessing the ECD B child's holistic development.

Table10: How ECD teachers assess children's holistic development.

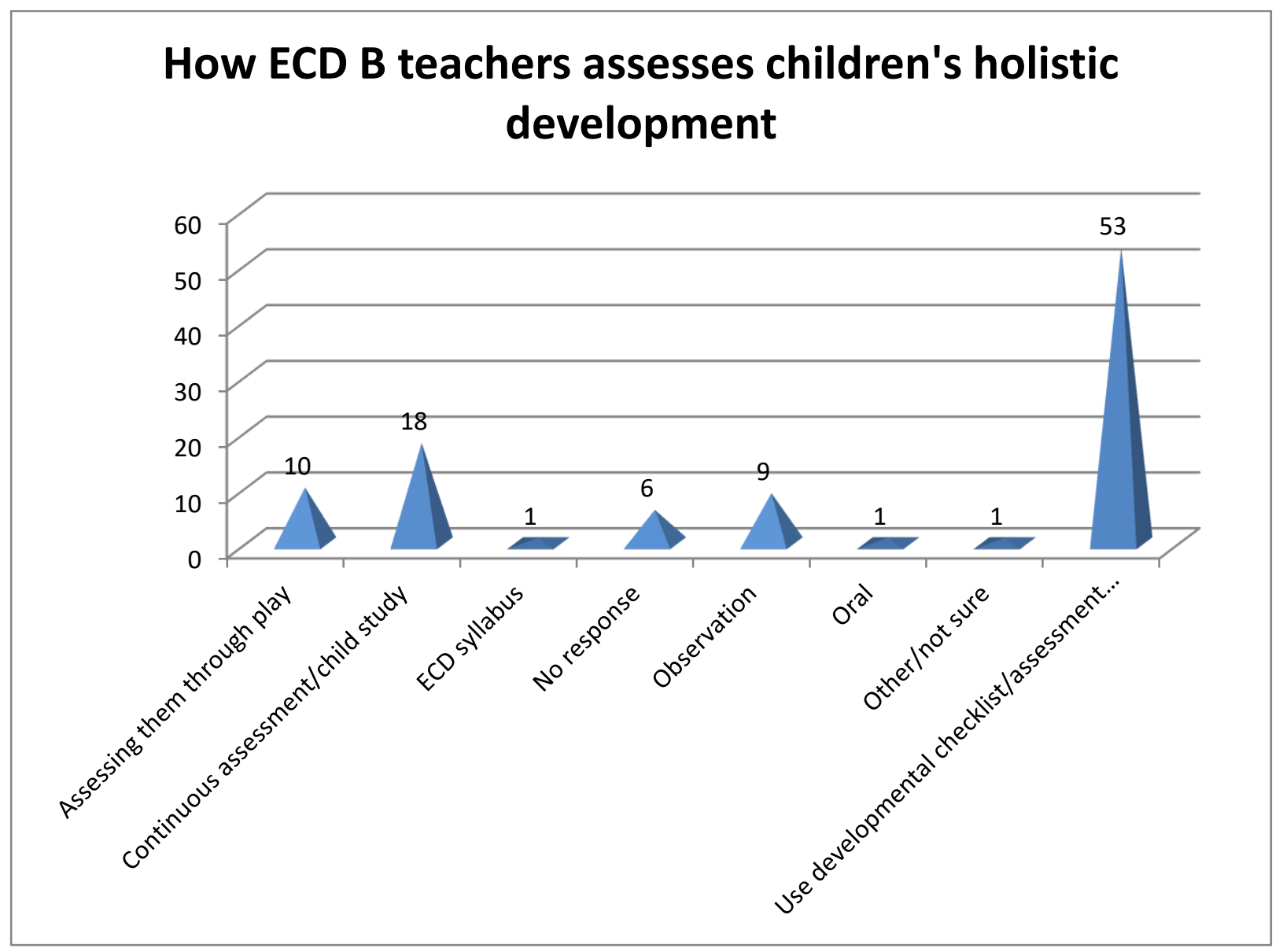

The trend across all the ten provinces revealed that the support the ECD B teachers get from MoPSE is inadequate $(53 \%)$ while those who feel the support is adequate is $45 \%$. Two percent did not respond.

Responses from ECD B teachers indicated that there is inadequate support from MoPSE in terms of:
a. Allowances for para-professionals;

b. Materials and equipment;

c. ECD B facilities and infrastructure;

d. Capacity building workshops;

e. Supervision by Ministry officials; and

f. Provision of circulars.

Those that perceived the support as adequate explained that:

a. Workshops are carried out for ECD B teachers; 
b. Adequate provision of the ECD syllabus; and

c. Adequate provision of ECD kits by MoPSE through UNICEF.

Once the teachers feel that the support given to them is not adequate they feel insecure and incapacitated to execute their duties effectively and this has a negative impact on quality output. Some teachers have gone for some months without allowances because parents are financially constrained and cannot pay them. This has resulted in some teachers abandoning children and looking for better paying jobs.

\section{Table 11: Support given to ECD B teachers by the Ministry of Primary and Secondary Education}

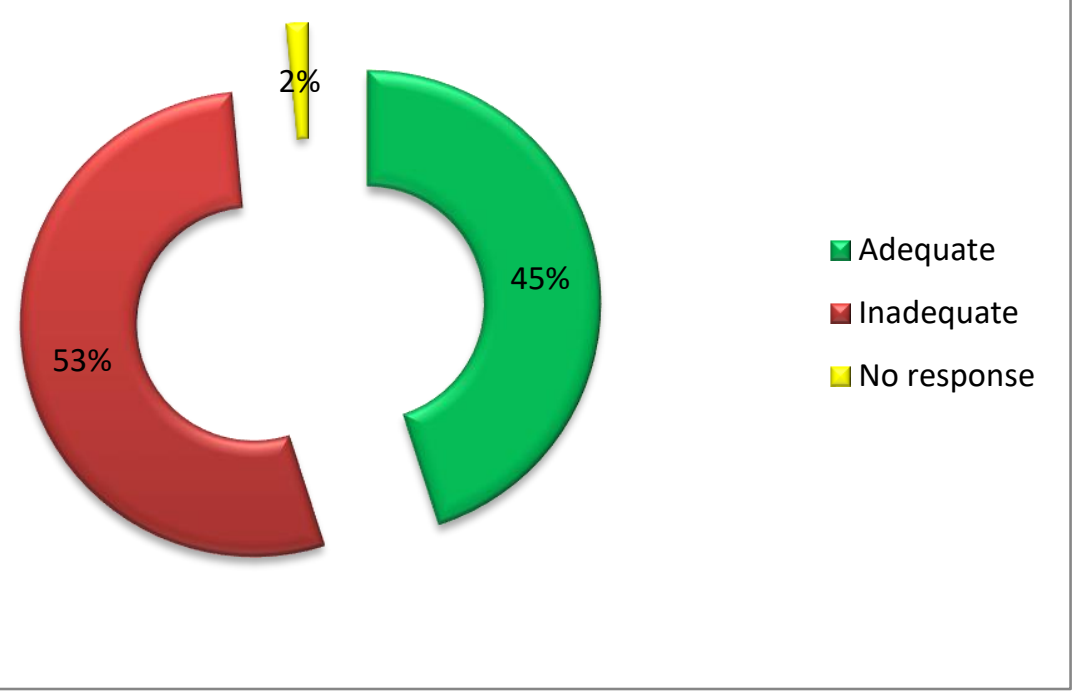

The study revealed that ECD $B$ teachers are also supported by MoPSE through staff development activities. Some of the workshops are mounted by the government through the sponsorship of Non-Governmental Organisations and UNICEF. Professional development should be made mandatory and provided by a range of different providers, with different modes, on a broad range of topics. Quality teaching is ensured through the recruitment of high caliber candidates, the provision of high quality initial teacher education and support throughout their career in the form of continuous professional development. Teachers are the most important educational resource and a critical determinant of quality.

The respondents also indicated that support also comes through supervision. The teachers are supervised by the school head and
Teacher-in-charge through lesson observations. After the lesson observation, they use school based supervision form and write narrative notes for the teacher which are then used to improve the quality of teaching and learning. The teacher is also supervised by way of record books or documents that are submitted to the same authorities.

\section{Discussion}

The results of the study showed that most Zimbabwean ECD B classes are manned by untrained teachers who have inadequate training and, yet the presence of trained and experienced teachers has been consistently linked to high quality interactions between children and adults. Responses from trained staff with specialization in ECD were that they engage in substantially more developmentally appropriate interactions with children than their untrained counterparts. This is a cause for 
concern because it means quality ECD provision will remain a distant dream for some children. Reasons given for this were that the training and education of staff affects the quality of services and outcomes primarily through the knowledge, skills and competencies that are transmitted and encouraged by practitioners.

The study found that the majority of ECD B teachers are inexperienced and as such they struggle with the interpretation of the ECD documents like: circulars and syllabus as well as scheming, planning, implementation and assessment of children's holistic development. Thus, the quality of ECD B provision is negatively affected. Therefore, staff development workshops at school, cluster and district levels should be held regularly with such teachers in order to continuously equip them with skills on how to handle ECD B children. Workshops content can focus on syllabus interpretation, scheming, planning implementation and record keeping. Facilitators at such workshops should be well versed in the area so that the teachers can gain valuable information that is meant to benefit children. A national workshop can be held at least once a year with representatives from all districts who will cascade the information to their schools. Being a trained teacher is not a sufficient condition for improving quality or for optimizing the benefits of ECD on children's outcomes. On-going professional development provided in sufficient length and intensity is important in enhancing staff competence. In addition, ongoing training leads to acquisition of new knowledge, continuous improvement of educational practice and deepening of pedagogical understanding. For these reasons, continuing professional development opportunities need to be tailored to meet staff needs and should be made available to all ECD personnel. All staff should be able to access pedagogical support programmes e.g. counseling, collaboration with other social and educational agencies at a local level. Some participants indicated that being experienced in the classroom has made them more effective because they have had extended time to test procedures and lessons on several cohorts of ECD children. The trial and error has led them to find the most effective and efficient techniques that they use and perfect over time.

In addition to teaching experience, working conditions can influence the satisfaction of professionals with their workplace which is likely to affect the ability and willingness to provide high quality relationships and attentive interactions with children. High staff turnover disrupts the continuity of care, negates professional development efforts, harms overall quality and negatively affects child outcomes.

Findings also revealed that generally ECD $B$ teacher-pupil ratios in Zimbabwe are high. Although Zimbabwe annunciated a policy on mandatory ECD $B$ attendance, building of ECD classrooms has not kept pace with the increase in the children's population. In this scenario, schools have had to expand class sizes, as well as the ratio of children to teachers in order to accommodate large numbers. While compulsory ECD attendance in Zimbabwe is a noble idea, the intended gains are being eroded by poor performance due to lack of observance on the ideal number of pupils per teacher resulting from high enrolments and declining number of teachers. The quality of education provided has been a major concern due to congested classrooms resulting from high enrolments. Parents also seem to be aware of the importance of ECD hence the increase in numbers of children attending ECD B. With such enrolments and reduced number of teachers, the available teachers face serious obstacles in an attempt to deal with overcrowded classes. These high ECD B enrolments have caused low efficiency in the schools which is one of the reasons for the poor quality of ECD B provision. Where teacher-pupil ratio is high chances are that the teacher is not able to stimulate all the children adequately and is also not able to provide adequate developmentally appropriate materials for 
children to play with. High teacher-pupil ratios result in less communication, interaction and coordination which contribute to lower achievement. Individual differences of children are not catered for and the result is that the teacher teaches formal subjects. Holistic development of children is thus deprived. Small group sizes are an indicator of quality in ECD B provision. In order to meet the challenge of increasing numbers of children, Zimbabwe will need additional teachers to lower the high teacher-pupil ratios to levels that can guarantee quality education. Low teacher-pupil ratios are usually found to enhance ECD B quality and facilitate developmental outcomes for children. Respondents highlighted that quality provision in a context with low teacher-pupil ratios has the following outcomes:

- Better teacher - pupil interactions;

- Less stress for staff; and

- Better child development.

Better ratios (fewer children per adult and more qualified teachers) are associated with higher language, cognitive and social skills of children cared for. When children are placed in larger groups there is less adult/child interaction, less social stimulation, less active involvement in experiences and higher levels of apathy and uncooperative behavior. High teacher- pupil ratios force teachers to be more managerial and controlling with children.

The study indicated that some ECD B teachers do not use the National ECD syllabus to teach children. They are actually teaching ECD B children formal reading, writing and mathematics which is contrary to Statutory Instrument 106 of 2005 section 10 (2) which prohibits any teaching of that nature to ECD B children. Using a developmentally appropriate curriculum is one of the determinants of high quality ECD provision. ECD B children who are taught academic subjects are thus denied quality learning. An overly structured academic focus in ECD can prevent children from developing the social and emotional skills they need. Studies show that children can experience stress in environments with a predominant focus on academic training (Gray, 2015). Although more academic approaches result in early achievement gains especially in literacy, they can be followed by detrimental outcomes particularly in terms of social and emotional wellbeing (Farran and lipsey, 2015).

Other respondents highlighted the importance of appropriate facilities which are important for effective curriculum implementation. Appropriate and adequate resources as well as their effective use are an indicator of a high quality programme for young children. Findings from provinces also revealed that most ECD centres are characterised by inadequate facilities relative to the population of children due to financial considerations. Some ECD B classes operate in buildings designed for other purposes rather than as classrooms. All these factors negatively affect the quality of ECD B provision.

\section{Conclusion}

The focus of the study was to assess quality issues in the provision in ECD B in Zimbabwe. This was done through the use of structural and process quality indicators for ECD. The study concluded that both structural and process indicators are not up to standard thus affecting the effectiveness and efficiency of ECD B provision in Zimbabwe. Specifically, the quality of ECD B provision has been compromised because of high teacher-pupil ratio, inadequate human, material and financial resources.

\section{References}

Berger, K.S.(2000) The Developing Person. New York. Wool Folk.

Bredekamp, S. (1993) Developmentally Appropriate Practice in Early Childhood Programmes. Serving Children From Birth Through To 8 Years. Washington. National Association For The Education Of Young Children.

Docket and Farmer (2000). Programming and Planning in ECD Settings. Sydney. Harcourt Brace. 
Farrar, K. and Lipsey, C. (2015) Handbook of Government of Zimbabwe (2013) Constitution Child Development Research and its Impact on of Zimbabwe. Harare. Government Printers.

Policy. Oxford. University Press.

Gunilla, D, Moss, P. and Pence, A. R.(1999)

Gray,P. (2015) The Growing Up Child. New York. Harper Press.

Beyond Quality in Early Childhood and Care: England. Falmer Press.

Government of Zimbabwe (2015) Annual Lamb, (2000) Quality Issues in Early Childhood Statistics Report. Harare. Government Printers. Education. London. McMillan.

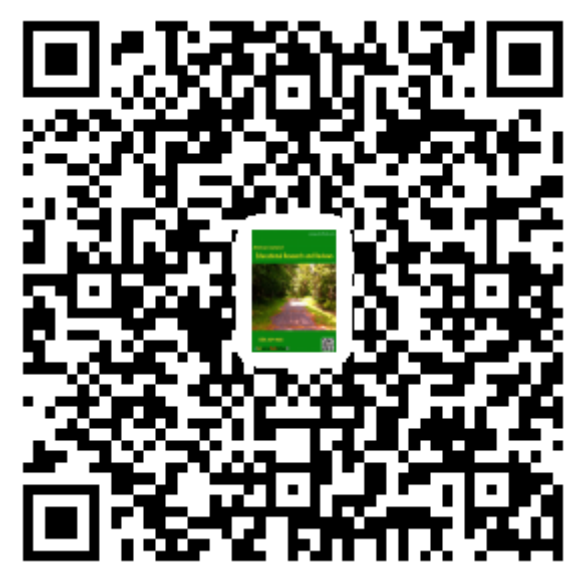

